\title{
APRENDIZAGEM BASEADA EM PROJETOS COMO ESTRATÉGIA DE ENSINO HÍBRIDO NO CURSO DE ARQUITETURA E URBANISMO
}

\author{
PROJECT BASED LEARNING AS A STRATEGY OF BLENDED LEARNING IN THE \\ ARCHITECTURE AND URBANISM COURSE
}

\author{
João Lemos Cordeiro Sayd ${ }^{1 *}$, Pedro Canal Filho ${ }^{2}$, \& José Osvaldo Costalonga Neto ${ }^{3}$ \\ ${ }^{1}$ Centro Universitário Salesiano - UniSales, ${ }^{2}$ Instituto Goia, ${ }^{3}$ Sem filiação.

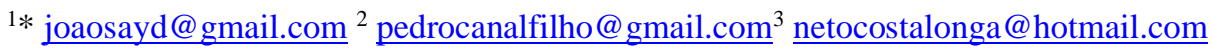

\section{ARTIGO INFO.}

\section{Recebido em: 27.09.2021}

Aprovado em: 26.10.2021

Disponibilizado em: 16.12 .2021

\section{Palavras-chave:}

Metodologia ativa; Projeto de extensão; Introdução ao projeto arquitetônico.

\section{KEYWORDS:}

Active learning; Extension project; Introduction to architectural project.

*Autor Correspondente: Sayd, J. L. C.

\section{RESUMO}

A pesquisa identifica potencialidades e limitações de aplicação do método de Aprendizagem Baseada em Projetos (ABP) no segundo período do curso de Arquitetura e Urbanismo em uma instituição de ensino superior, no contexto de aprofundamento do modelo de ensino híbrido. Desse modo, foram levantadas as principais questões teóricas que envolvem o método ABP e estudadas duas atividades desenvolvidas com os alunos do segundo período a partir do mesmo objetivo (desenvolver um método/metodologia para a execução de projetos de arquitetura), em modelos de ensino com diferentes cargas horárias presencial e à distância. Ambas as atividades se utilizaram de conceitos dessa metodologia ativa de aprendizagem, mas com organizações e temáticas diferentes, em certa medida decorrentes da migração do modelo de ensino. A primeira atividade é denominada "Meu Lugar", de caráter lúdico e individual e a segunda atividade é um projeto de extensão, estruturado a partir de uma demanda real. Observou-se que as duas estratégias são importantes e complementares, pois o projeto "Meu Lugar" possibilita avaliar o aluno individualmente, a partir de interesses pessoais e de proposições conceituais mais livres, enquanto o projeto de extensão desenvolve o trabalho em equipe, o atendimento de demandas reais e o respeito às legislações e normas vigentes, bem como desejos e necessidades de um destinatário específico. Em ambos os casos, notou-se também a necessidade de atividades e desafios complementares, que subsidiem um aparato técnico, especialmente de representação.

\begin{abstract}
The paper identifies potentialities and limitations of application of the Project Based Learning (PBL) method in the second period of the Architecture and Urbanism course in an institution of higher education, in the context of deepening the blended learning model. In this way, the main theoretical issues involving the PBL method were raised and it was studied two activities developed with students of the second period with the same objective (developing a method / methodology for the execution of architectural projects), in the classroom and blended learning models. Both activities used concepts from this active learning methodology, but with different organizations and themes, to some extent resulting from the migration of the teaching model. The first activity is called "Meu Lugar", of a playful and individual character and the second activity is an extension project, structured based on a real demand. It was observed that the two strategies are important and complementary, as the "Meu Lugar" project enables the assessment of the individual student, based on personal interests and freer conceptual propositions, while the extension project develops teamwork, service real demands and respect for current legislation and regulations, as well as the desires and needs of a specific recipient. In both cases, it was also noted the need for complementary activities and challenges, which support a technical apparatus, especially representation.
\end{abstract}




\section{INTRODUÇÃO}

Esta pesquisa abordará a aplicação do método de Aprendizagem Baseada em Projetos (ABP) em componentes curriculares que tratam da introdução ao projeto de arquitetura, no segundo período de um curso de Arquitetura e Urbanismo em uma instituição de ensino superior (IES) confessional, no contexto de aprofundamento do ensino híbrido - caracterizado pela substituição de parte da carga horária de ensino presencial por ensino à distância. A ABP é um método notadamente eficaz para elevar a qualidade do ensino, graças ao aumento da motivação estudantil e à articulação entre teoria e prática, sendo apontada como um paradigma emergente nos processos de ensino e aprendizagem (Masson, Miranda, Munhoz, \& Castanheira, 2012; Bender, 2014). Alinhado a este método, o curso de Arquitetura e Urbanismo é essencialmente prático. Este caráter prático caracteriza a formação dos profissionais arquitetos desde as suas origens, em todos os períodos e lugares, e tem o contato entre mestre e aprendiz como um elemento fundamental. A importância da presencialidade no ensino de arquitetura levou o Conselho de Arquitetura e Urbanismo do Brasil (CAU/BR) a não reconhecer profissionais arquitetos e urbanistas formados no ensino à distância (CAU/BR, 2019a).

Por outro lado, a demanda por cursos superiores com menos aulas presenciais tem aumentado ao longo dos últimos anos no Brasil e no mundo. Isto decorre de transformações políticas e econômicas, bem como de mudanças culturais relacionadas à aceleração da rotina, ao aumento dos tempos de deslocamento, às transformações no mercado de ensino superior e sobretudo às novas possibilidades ofertadas pelas Tecnologias de Informação e Comunicação (TICs). Esta tendência foi reforçada a partir da Portaria n 2.117/2019, do Ministério da Educação, que possibilitou a ampliação da carga horária à distância dos cursos presenciais, de $20 \%$ para $40 \%$ (MEC, 2019).

Diante deste cenário, questiona-se como conciliar a qualidade necessária à formação do profissional Arquiteto e Urbanista com a redução da carga horária presencial, em disciplinas como ateliês de projeto, laboratórios e visitas de campo. Nesse sentido, temos como hipótese que a Aprendizagem Baseada em Projetos é a metodologia ativa mais eficaz para esta transformação do curso de Arquitetura e Urbanismo e que esta metodologia, de certo modo, sempre foi intensamente aplicada na formação do arquiteto e urbanista.

Propõe-se, então, um retorno às origens da formação profissional, conciliando os métodos sistematizados pela ABP como forma de conjugar as competências de caráter menos aplicado com as atividades de projeto. Esta estratégia consistiria em uma radicalização, ou aprofundamento, do que já é praticado em algumas escolas de arquitetura no Brasil e no mundo.

O aprofundamento da ABP no curso de Arquitetura e Urbanismo na IES preconiza que os projetos desenvolvidos pelos aprendizes sejam sempre que possíveis projetos de extensão, e tenham, portanto, destinatários reais. Conforme a definição dos autores, os destinatários do projeto de arquitetura são divididos em categorias, podendo um destinatário estar simultaneamente em mais de uma destas, a saber: 
- Demandante: o responsável pela solicitação e validação do projeto, que no mercado profissional corresponderia à figura do cliente. No projeto de uma escola, por exemplo, o demandante seria o dono da escola.

- Usuário: aquele que utilizará efetivamente o espaço projetado. No exemplo da escola, o usuário seria a comunidade acadêmica.

- Público: quem usufrui esteticamente da obra projetada, incluindo além dos usuários outras pessoas que não adentram o edifício. No caso da escola, o público seria formado pelos transeuntes que percebem o edifício na paisagem, e mesmo aqueles que verão o edifício estampado em peças publicitárias ou em revistas especializadas de arquitetura.

A ABP é uma estratégia de ensino e aprendizagem sistematizada no século XX e mundialmente disseminada a partir do século XXI, que passa a exigir muito mais empenho dos alunos e dos professores. Esta necessita que o professor reflita sobre a atividade docente e mude a sua postura tradicional de especialista em conteúdo para treinador de aprendizagem, e que os estudantes assumam maior responsabilidade por sua própria aprendizagem, com a compreensão de que o conhecimento obtido com o seu esforço pessoal será mais duradouro do aquele obtido apenas por informações de terceiros. Dentre as principais características da ABP destaca-se: o aluno como protagonista do processo de aprendizagem; o seu desenvolvimento através de grupos de estudo ou trabalho; o fato de ser um processo ativo, interdisciplinar e cooperativo, focado no aluno; e a resolução de problemas reais ou realistas (Masson et al., 2012; Bender, 2014).

Nesse sentido, a metodologia exige acompanhamento/tutoria do educador e o contato entre os alunos, pois parte-se do princípio de que os desafios propostos em forma de desenvolvimento de projetos sejam realizados, grande parte, em equipe. As trocas presenciais não são completamente supridas com os estudos ou mesmo encontros virtuais e a mediação do professor também fica prejudicada no ambiente virtual.

\section{Objetivos e Metodologia}

O objetivo principal desta pesquisa é identificar potencialidades e limitações do método de Aprendizagem Baseada em Projetos (ABP) para o curso de Arquitetura e Urbanismo, especialmente a partir da implementação do modelo híbrido, onde cerca de 1/3 da carga horária das aulas é realizada à distância $(\mathrm{EaD})$.

Para isso, foram estabelecidos os seguintes objetivos específicos:

- Caracterizar o método de ensino denominado Aprendizagem Baseada em Projetos (ABP), observando suas relações com a formação em Arquitetura e Urbanismo e com o modelo de ensino híbrido;

- Relatar e avaliar as experiências das disciplinas introdutórias ao projeto de arquitetura no segundo período do curso de Arquitetura e Urbanismo de uma instituição de ensino superior confessional durante o período de transição do para o modelo de ensino híbrido;

- Divulgar, de modo sistematizado, as experiências pedagógicas do curso de Arquitetura e Urbanismo desta instituição de ensino superior.

A pesquisa, de natureza qualitativa, foi realizada em duas etapas:

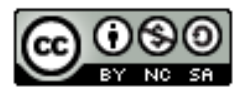


Citação (APA): Sayd, J. L. C., Canal, P., Filho, \& Costalonga, J. O., Neto. (2021). Aprendizagem baseada em projetos como estratégia de ensino híbrido no curso de arquitetura e urbanismo. Brazilian Journal of Production Engineering, 7(4), Edição Especial: "Educação 5.0: Inovação e metodologias ativas para o ensino superior" 46-64.

1. Revisão de literatura para definição do modelo de ensino híbrido e como forma de aprofundar o conhecimento quanto às metodologias ativas, especialmente a ABP/PBL e conceitos relacionados à aprendizagem ativa e seus desdobramentos, incluindo formas e métodos de avaliação, observando suas interrelações com as práticas de ensino tradicionais no campo da Arquitetura e do Urbanismo.

2. Relato e avaliação das experiências das disciplinas introdutórias ao projeto de arquitetura no segundo período do curso de Arquitetura e Urbanismo de uma IES confessional durante o período de transição do antigo para o novo modelo pedagógico/institucional, baseado no ensino híbrido e em metodologias ativas de aprendizagem;

\section{A ABP na formação em arquitetura e no ensino híbrido}

A metodologia da Aprendizagem Baseada em Projetos foi sistematizada no ano de 1900 pelo filósofo estadunidense John Dewey (1859-1952), que comprovou a eficácia do desenvolvimento intelectual, emocional e físico através da resolução de problemas reais por parte dos alunos, ou aprendizes. O filósofo estabeleceu que ‘aprender fazendo' é uma estratégia mais eficaz do que a transmissão do conhecimento teórico de forma antecipada e desvinculada e da sua aplicação real. Durante o século XX, esta premissa foi reforçada por outras teorias de ensino e aprendizagem, notadamente o Construtivismo e Construcionismo. Estas teorias preconizam que o conhecimento é relativo, desenvolvido pelo aprendiz a partir de suas experiências pregressas e visões de mundo. Portanto, cada indivíduo tem suas próprias necessidades de aprofundar e integrar os conhecimentos (Ribeiro, 2005; Masson et al., 2012).

O método parte do pressuposto de que a aprendizagem é um processo ativo por parte do aluno e que, portanto, depende fundamentalmente do seu interesse e motivação. As ações do aluno são mais relevantes do que aquelas do professor. Portanto, a ABP relaciona-se mais a aspectos intrínsecos do aprendiz, e para ser bem-sucedida a aprendizagem deve ser autogerada, auto conduzida e autossustentada. Neste processo, o papel do professor consiste sobretudo em elencar um problema ou projeto e orientar na sua resolução ou elaboração, possibilitando o máximo de autonomia ao aprendiz, que eventualmente pode até escolher a questão a ser trabalhada. Para motivar o aluno, é comum que o problema ou projeto envolva um contrato moral com terceiros, ou seja, atenda a demandas reais - associando assim a criação individual à utilidade social (Masson et al., 2012; Bender, 2014).

Um elemento característico da Aprendizagem Baseada em Projetos é a âncora - uma informação que dá o pontapé inicial para o desenvolvimento do projeto, de modo que a narrativa seja capaz de despertar o interesse dos aprendizes pela atividade. A âncora pode ser uma notícia de jornal, correspondência, publicação científica, entre outros, que costuma evidenciar a aplicação prática do projeto a ser desenvolvido. $\mathrm{O}$ fato de os aprendizes perceberem que o seu projeto terá relevância no mundo real é um importante indutor para aumentar seu interesse e engajamento na atividade. A partir da âncora, é estabelecida uma questão motriz, que serve para orientar os aprendizes no desenvolvimento do projeto, direcionando seus esforços para não se perderem em atividades que não sejam produtivas para o resultado pretendido. Portanto, o conjunto da âncora com a questão motriz deve permitir aos aprendizes identificar quais informações, e em qual profundidade, são necessárias ao projeto (Bender, 2014).

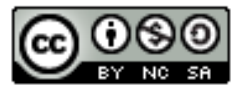


Citação (APA): Sayd, J. L. C., Canal, P., Filho, \& Costalonga, J. O., Neto. (2021). Aprendizagem baseada em projetos como estratégia de ensino híbrido no curso de arquitetura e urbanismo. Brazilian Journal of Production Engineering, 7(4), Edição Especial: "Educação 5.0: Inovação e metodologias ativas para o ensino superior" 46-64.

Outro aspecto importante para despertar o interesse e engajamento dos aprendizes é sua autonomia, que pode consistir já na liberdade de escolha dos projetos a serem desenvolvidos ou, a partir de um projeto pré-determinado, na elaboração da questão motriz. O momento adequado para que os aprendizes intervenham no direcionamento da atividade é uma decisão sensível que cabe ao professor, considerando os objetivos pedagógicos e a maturidade dos estudantes. Igualmente, a aplicação da ABP demanda mais preparo por parte dos professores, e na medida em que estes tornam-se mais familiares com a metodologia, mais liberdade podem proporcionar aos aprendizes (Ribeiro, 2005; Bender, 2014).

Os projetos têm a possibilidade de ensejar no seu desenvolvimento múltiplas atividades de ensino e aprendizagem. Esta característica deve ser aproveitada pelo professor no planejamento do desafio para abarcar diversos elementos curriculares, articulando-os com as tarefas e produtos intrínsecos ao projeto desenvolvido. É comum que diferentes projetos mobilizem os mesmos conhecimentos, com diferentes níveis de profundidade. Portanto os conhecimentos, ou conteúdos, não são esgotados em cada momento e nem tampouco tratados de maneira sequencial ao longo do curso. Assim, a ABP é capaz de articular variados conhecimentos, habilidades e atitudes, proporcionando ao aprendiz o desenvolvimento de múltiplas competências (Masson et al., 2012; Bender, 2014).

Neste contexto, o papel principal do professor consiste em planejar as atividades e oferecer assistência estruturada ao longo das diferentes etapas do processo. Assim, as aulas expositivas acabam relegadas a segundo plano, quase sempre restritas a explanações instrucionais sobre as atividades a serem desenvolvidas. É comum que os professores fiquem sobrecarregados e sob maior estresse do que nos formatos convencionais, pois o encaminhamento das atividades usualmente envolve mudanças nas instruções, com eventual perda de controle, em certa medida, sobre o processo de ensino e aprendizagem. Na ABP o professor é menos um palestrante e mais um facilitador, mediador ou orientador, enquanto a equipe aprende de forma cooperativa, a partir das atividades desenvolvidas (Ribeiro, 2005; Masson et al., 2012; Bender, 2014).

O trabalho em equipe é um elemento fundamental da ABP. Portanto os aprendizes devem ser capazes de organizar-se, elencando diferentes papéis para os membros de cada time. Saber liderar e servir, bem como compreender suas vocações e fraquezas, são atributos essenciais para o bom resultado do processo de aprendizagem, que por sua vez refletem-se na qualidade do produto final. Portanto, é comum e esperado que as equipes elejam membros para atuar como líderes (Ribeiro, 2005; Masson et al., 2012; Bender, 2014).

Embora os projetos possam apresentar muitas variações e particularidades, com elementos próprios de acordo com cada realidade, Bender (2014) elenca as seguintes etapas para um projeto padrão, desenvolvido no formato da ABP:

- Introdução e planejamento em equipe;

- Coleta de informações;

- Protótipo / avaliação inicial;

- Segunda fase de pesquisa; 
- Produto final;

- Publicação.

A etapa final é um elemento característico da $\mathrm{ABP}$, que consiste na publicização dos trabalhos, através da sua exposição para a comunidade, disponibilização em plataformas online e apresentação em seminários. A publicação dos resultados tem grande potencial para engajar os aprendizes no desenvolvimento do projeto. Esta etapa é importante também na promoção de competências atitudinais, como postura, ética, pontualidade, comunicação oral, inteligência emocional, entre outros, fundamentais ao exercício profissional (Masson et al., 2012; Bender, 2014).

A avaliação na ABP possui certas particularidades em relação aos métodos mais convencionais de ensino e aprendizagem. Há diversas alternativas possíveis, que devem sempre abarcar notas individuais e coletivas (Ribeiro, 2005; Bender, 2014).

Dentre as formas de avaliação mais usuais na ABP destacam-se as rubricas, que consistem em procedimentos envolvendo critérios específicos de desempenho, usualmente categorizados em diferentes níveis. O conjunto de rubricas adequado deve abarcar todos os procedimentos relevantes na resolução do problema ou elaboração do projeto. Outro modo de avaliação importante na ABP é a autoavaliação reflexiva, na qual o aprendiz mede seu rendimento a partir de critérios determinados pelo professor. Esta avaliação pode ser numérica ou dissertativa. Igualmente, é comum a avaliação por pares, na qual os aprendizes elencam sua percepção sobre o desempenho dos colegas da equipe. Outro modo comum de avaliação na ABP é o portfólio um compilado organizado pelo aprendiz das atividades desenvolvidas ao longo do projeto, com um balanço sobre seus pontos fortes e fracos, para apreciação do professor. Os portfolios podem ser apresentados também no formato de seminários (Ribeiro, 2005; Masson et al., 2012; Bender, 2014).

Em todos os casos, é fundamental que o professor forneça feedbacks aos alunos. Estes, quando realizados ao longo do projeto são chamados de feedbacks formativos, e têm a função de orientar o aluno sobre seus erros e acertos, estimulando-o a avançar nas atividades. Já os feedbacks finais têm o propósito de classificar os alunos quanto ao seu rendimento, e são chamados somativos (Ribeiro, 2005; Masson et al., 2012; Bender, 2014).

\subsection{Breve histórico da formação em Arquitetura e Urbanismo}

Embora a Aprendizagem Baseada em Projetos tenha sido sistematizada e difundida somente ao longo do século $\mathrm{XX}$, muitos aspectos deste método sempre estiveram em grande medida presentes na formação profissional dos arquitetos e urbanistas. Notadamente, a transdisciplinaridade, a relação entre mestre e aprendiz, a formação através da prática profissional, o tratamento de questões amplas, que ultrapassam o campo profissional e envolvem o conjunto da sociedade, e até mesmo as etapas de projeto.

Os primeiros arquitetos surgiram junto com as primeiras cidades. Na antiguidade, eles dominavam diversas áreas do conhecimento, sendo filósofos, matemáticos, físicos, astrônomos, historiadores e escribas dentre outros. Além da transdisciplinaridade, tinham em comum a 
Citação (APA): Sayd, J. L. C., Canal, P., Filho, \& Costalonga, J. O., Neto. (2021). Aprendizagem baseada em projetos como estratégia de ensino híbrido no curso de arquitetura e urbanismo. Brazilian Journal of Production Engineering, 7(4), Edição Especial: "Educação 5.0: Inovação e metodologias ativas para o ensino superior" 46-64.

estreita relação entre mestre e aprendiz. Esta relação foi reforçada na Europa medieval, quando se organizaram em oficinas e corporações de ofício. Estes arquitetos já se dedicavam apenas à arte de projetar e construir edifícios. A aprendizagem era prática, voltada às demandas reais e realizada no local de trabalho (Mumford, 2008; Benévolo, 2015).

No Renascimento, com o avanço das técnicas de desenho, surgiu a distinção entre os arquitetos e demais profissionais envolvidos na construção. As obras passaram a ser concebidas nos ateliês de arquitetura, e os desenhistas responsáveis pela criação herdaram a alcunha de arquitetos, enquanto a responsabilidade pela construção foi compartilhada com outros profissionais. Este distanciamento do canteiro de obras provocou, no início do Século XX, uma crise na profissão, devido ao conflito entre a linguagem arquitetônica e as novas técnicas construtivas. Então, no período entre guerras o movimento moderno reaproximou os arquitetos do domínio das técnicas e materiais construtivos, acrescentando ainda a prática do urbanismo e a preocupação com questões sociais, como o direito à cidade e à moradia (Benévolo, 1998; Hall, 2001; Mumford, 2008; Benévolo, 2015).

As seis etapas elencadas por Bender (2014) para um projeto típico da ABP também têm similaridades com as fases de elaboração dos projetos arquitetônicos, nos quais a formação das equipes e coleta de informações são o primeiro passo, seguido pela feitura de projetos em etapas subsequentes. Cada etapa do projeto é sucedida por modificações, orientadas pelas novas informações, que se tornam necessárias na medida que avança o nível de detalhamento. Finalmente, a última etapa do projeto consiste na sua apresentação definitiva ao cliente ou, no âmbito acadêmico, ao seminário final.

Hoje, as Diretrizes Curriculares Nacionais (DCN) dos cursos de Arquitetura e Urbanismo determinam a organização dos conteúdos curriculares em dois núcleos: Conhecimentos de Fundamentação e Conhecimentos Profissionais. Apesar desta divisão, a DCN recomenda a inter penetrabilidade destes dois núcleos de conhecimento (MEC, 2010). Portanto, embora a legislação brasileira reproduza a noção de conhecimento compartimentado na formação do arquiteto e urbanista, esta avança (ou retroage, considerando o histórico da formação profissional) ao reconhecer a importância da indissociabilidade entre estes núcleos.

\subsection{Desafios para a formação em arquitetura no século XXI}

Os mapas do ensino superior no Brasil, publicados anualmente pelo SEMESP, previam desde o final da década de 2010 que mudanças profundas ocorrerão nos cursos de graduação durante os próximos anos, a fim de atender às transformações no mercado de trabalho provocadas pelo surgimento e disseminação de novas tecnologias - relacionadas sobretudo ao universo digital e à inteligência artificial. Presume-se a completa reformulação, até 2030, de cursos como Arquitetura e Urbanismo e Engenharia Civil. Segundo especialistas, o mundo acadêmico deve aproximar-se da cultura maker, ancorada no princípio de aprender fazendo (Learn by Doing) (Reis, 2017).

A reestruturação do processo de ensino e aprendizagem é um reflexo das novas configurações sociais e da inserção progressista das tecnologias no cotidiano pessoal, acadêmico e profissional das pessoas. As modificações que recaem sobre o atual sistema de ensino são uma reação à

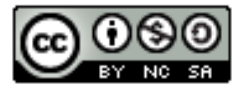


revolução informacional ou tecnológica, considerada a terceira etapa da revolução industrial, na qual se inserem práticas pedagógicas que estimulam o acadêmico a transpor para o cotidiano profissional o conhecimento por ele produzido (Soares, 2001).

O plano estratégico que mais vem sendo associado às filosofias das IES defende a implantação de um sistema de engajamento estratégico e ativo que inclui práticas direcionadas aos alunos com o intuito de formá-los no método Learn by Doing, estimulando-os e os conduzindo a uma reflexão acerca das atividades desenvolvidas na universidade, o que os capacita a aplicar seus conhecimentos teóricos a empreendimentos práticos em uma variedade de ambientes (Reese, 2011). A motivação do aluno é provocada pela capacidade de fazê-lo sentir-se desafiado a solucionar problemas, desta forma ele desloca-se da percepção estática e busca novas possibilidades de compreensão de mundo ou do objeto em análise (Soares, 2001).

Para além do ensino de Arquitetura e Urbanismo, as mudanças tecnológicas decorrentes da disseminação do acesso à internet vêm desde o final da década de 1990 transformando os modos de ensino e aprendizagem em diferentes níveis, com a ampliação do ensino à distância. Esta mudança tornou-se mais acentuada a partir das duas primeiras décadas do século XXI. Neste processo, muitos cursos tradicionais têm incorporado metodologias de ensino à distância, transferindo parte da carga horária presencial para o ambiente virtual de aprendizagem. A utilização do ensino à distância como elemento complementar ao ensino presencial deu origem ao conceito de ensino híbrido (Horn \& Staker, 2015).

Este trabalho adota a definição de ensino híbrido de Christensen, Horn e Staker (2013), que o distingue por três aspectos:

- Trata-se de um programa de educação formal, no qual uma parte do conteúdo e da aprendizagem ocorrem online e há algum controle do estudante sobre o processo de aprendizagem, sendo este relativo à escolha do lugar, da trilha de aprendizagem ou do seu ritmo (atividades assíncronas, sem horário determinado para ocorrer).

- Parte da aprendizagem é realizada presencialmente na instituição de ensino, acompanhada por um professor ou supervisor. Estas atividades são síncronas, têm um horário prédeterminado.

- Há uma integração, ou complementaridade, entre as atividades desenvolvidas online e aquelas desenvolvidas presencialmente. Esta coordenação entre as atividades síncronas e assíncronas pressupõe uma supervisão também do ambiente virtual, a fim de verificar se as atividades desenvolvidas pelo estudante antes do encontro são capazes de lhe dar o suporte necessário para o momento presencial.

A partir desta definição, importa ressaltar que o termo ensino híbrido vem sendo utilizado também com outros significados, que não são considerados nesta pesquisa, a saber:

- Cursos presenciais que utilizam o ambiente virtual para comunicação extraclasse, compartilhamento de material didático utilizado nas aulas, ou conteúdos e atividades suplementares (para saber mais ou aprofundar-se em determinado assunto).

- Cursos regulares que têm parte dos seus componentes curriculares presenciais e outra parte online, portanto sem integração entre as atividades dentro e fora da sala de aula. 
Citação (APA): Sayd, J. L. C., Canal, P., Filho, \& Costalonga, J. O., Neto. (2021). Aprendizagem baseada em projetos como estratégia de ensino híbrido no curso de arquitetura e urbanismo. Brazilian Journal of Production Engineering, 7(4), Edição Especial: "Educação 5.0: Inovação e metodologias ativas para o ensino superior" 46-64.

- Aulas síncronas que conjugam parte da turma na presença do professor e outra parte acompanhando de maneira remota através de videoconferência. Este formato foi difundido em razão das medidas de distanciamento social impostas pela pandemia de COVID-19 a partir de março de 2020.

Por outro lado, o Ministério da Educação utiliza os termos ensino presencial e ensino à distância para diferenciar os cursos regulares quanto à proporção da carga horária EaD. Neste sentido é comum que os cursos classificados como EaD, por ter alguma carga horária presencial, sejam divulgados como cursos híbridos. Esta definição pode ir ao encontro do significado do termo adotado neste estudo, visto que a definição de ensino híbrido não tem fundamento na legislação brasileiro e nem tampouco relaciona-se à distribuição da carga horária entre os diferentes formatos.

Atualmente, a ampla maioria dos cursos de ensino superior no Brasil, incluindo Arquitetura e Urbanismo, são considerados $\mathrm{EaD}$ quando sua carga horária à distância é superior a 40\% (MEC, 2019). Este máximo permitido tende a balizar as matrizes curriculares dos cursos presenciais nas IES privadas, uma vez que a proporção entre carga horária presencial e EaD influencia na precificação dos mesmos. Conforme mencionado, antes disso o CAU posicionou-se por não reconhecer como Arquitetos e Urbanistas os profissionais formados em cursos classificados como EaD, dado o caráter eminentemente prático da profissão, e sua vinculação com a vivência do espaço real (CAU/BR, 2019a). Porém, este entendimento do conselho encontra-se desafiado diante do aumento da carga horária à distância nos cursos presenciais. Ao mesmo tempo, a procura por cursos com maior carga horária virtual por parte dos estudantes relaciona-se não apenas à redução dos valore das mensalidades, mas também à maior flexibilidade de horários e à facilidade de acesso proporcionados pela disseminação de novas tecnologias de informação e comunicação.

Entre os desafios que impactam na implementação efetiva do ensino à distância, destacam-se a dificuldade de autonomia e cultura e autoestudo por parte dos aprendizes, bem como a falta de feedback dos professores quanto às atividades desenvolvidas online. Outro aspecto relevante é a necessidade de mudanças na abordagem pedagógica dos cursos, visto que não é adequado transferir a abordagem tradicional do ensino presencial para o modelo online. É, portanto, necessário mudar costumes e práticas, tanto por parte do aluno quanto pelos professores. Estas carências têm redundado na baixa participação e adesão dos alunos às atividades virtuais (Leandro \& Corrêa, 2018). Neste sentido, o ensino híbrido pode contribuir para aumentar o envolvimento do aluno e mitigar estas dificuldades, uma vez que relaciona as trilhas de aprendizagem independentes e presenciais.

Sobretudo, a ABP tem sido amplamente utilizada em muitos programas de ensino híbrido como forma de aumentar o desempenho dos estudantes, pelo fato de demonstrar a aplicação efetiva dos conhecimentos, bem como a inter-relação entre os diferentes componentes curriculares.

Em paralelo a estas transformações, o Plano Nacional de Educação (PNE) publicado em 2014 determinou que, até o ano de 2021, os projetos de extensão universitária correspondam a, no mínimo, 10\% da carga horária total dos cursos de graduação (Presidência da República, 2014). Frente a esta exigência, o CAU determinou que os projetos de extensão em Arquitetura e 
Urbanismo sejam supervisionados por um profissional Arquiteto e Urbanista, com o devido Registro de Responsabilidade Técnica (RRT) relativo ao cargo de Orientador de Projetos de Extensão em Arquitetura e Urbanismo, bem como o registro de todos os projetos realizados sob sua supervisão (CAU/BR, 2019b).

Neste contexto, a Aprendizagem Baseada em Projetos mostra-se um método com grande potencial para a formação dos Arquitetos e Urbanistas, atendendo às exigências de ampliação dos projetos de extensão e a interpenetrabilidade dos conhecimentos, bem como possibilitando em certa medida a substituição da carga horária de ensino presencial pelo estudo independente à distância. Além disso, o método resgata aspectos que sempre foram essenciais e estiveram presentes, em alguma medida, na formação destes profissionais. Porém, sua aplicação em sentido estrito no primeiro ano do curso esbarra em uma série de desafios e limitações, expostos a seguir.

\section{Duas experiências de introdução ao projeto de arquitetura}

Este estudo observa a execução de dois trabalhos acadêmicos realizados com os mesmos objetivos, no segundo período do curso de Arquitetura e Urbanismo de uma IES confessional nos anos de 2019 e 2020, quando houve a transição da estrutura curricular, com a redução da carga horária presencial e a ampliação da carga horária à distância $(\mathrm{EaD})$. O objetivo das atividades discentes era a sistematização e aplicação de uma metodologia de projeto de arquitetura, a partir de teorias e métodos já desenvolvidos, e da real necessidade da demanda/projeto proposto. Estas duas atividades estavam centradas em um componente curricular do período, porém a sua etapa final recebeu o aporte de outros componentes do mesmo semestre - a chamada integração horizontal entre os componentes curriculares, que nesta IES são chamados de projetos ou desafios, por compreendermos que o enfoque no desenvolvimento de competências diferencia estes componentes curriculares das disciplinas convencionais, cujo foco estaria centrado na transmissão de conteúdos (Costa, 2004; Souza, \& Biella, 2010).

A atividade do segundo semestre de 2019 foi realizada em um modelo com 16,6\% da carga horária $(\mathrm{CH}) \mathrm{EaD}$, enquanto na atividade desenvolvida no segundo semestre de 2020 este índice foi de $30,9 \%$. A primeira experiência foi um projeto conceitual gerado a partir da identificação com o perfil dos estudantes, denominado "Meu Lugar", e a segunda foi um Projeto Integrador de Extensão de uma Capela/Templo católico, demandado pela comunidade. Ambas foram aplicadas em turmas do segundo período em semestres diferentes e que possuíam o mesmo objetivo didático-pedagógico: a aplicação de uma metodologia/método de elaboração de projeto de arquitetura. Com o intuito de garantir e ampliar a qualidade do processo de ensino e aprendizagem, a ampliação da carga horária $\mathrm{EaD}$ foi acompanhada por igual aprofundamento dos métodos em ABP.

A carga horária EaD na IES não se concentra em componentes curriculares específicos, que seriam, portanto, considerados menos relevantes quanto à presencialidade. Pelo contrário, esta carga horária é igualmente distribuída entre a maioria dos componentes curriculares, com 
Citação (APA): Sayd, J. L. C., Canal, P., Filho, \& Costalonga, J. O., Neto. (2021). Aprendizagem baseada em projetos como estratégia de ensino híbrido no curso de arquitetura e urbanismo. Brazilian Journal of Production Engineering, 7(4), Edição Especial: "Educação 5.0: Inovação e metodologias ativas para o ensino superior" 46-64.

exceção do projeto de extensão, que foi integralmente presencial, e de componentes generalistas com uma pequena carga horária, que são de caráter eletivo e integralmente EaD (Tabela 1).

Tabela 1. Comparativo entre a carga horária destinadas aos dois trabalhos acadêmicos.

\begin{tabular}{|c|c|c|c|c|c|c|}
\hline Atividade & Componentes & $\begin{array}{c}\mathrm{CH} \\
\text { Presencial }\end{array}$ & $\begin{array}{l}\text { CH } \\
\text { EaD }\end{array}$ & $\begin{array}{c}\text { CH } \\
\text { Total }\end{array}$ & $\begin{array}{l}\text { Proporção } \\
\text { presencial }\end{array}$ & $\begin{array}{l}\text { Proporção } \\
\text { EaD }\end{array}$ \\
\hline \multirow{2}{*}{$\begin{array}{c}\text { Meu } \\
\text { Lugar } \\
\text { (2019) }\end{array}$} & Anteprojeto Arquitetônico & 25 & 5 & \multirow[b]{2}{*}{60} & \multirow[b]{2}{*}{$83 \%$} & \multirow[b]{2}{*}{$17 \%$} \\
\hline & $\begin{array}{c}\text { Documentação do Projeto } \\
\text { Arquitetônico }\end{array}$ & 25 & 5 & & & \\
\hline \multirow{3}{*}{$\begin{array}{l}\text { Projeto de } \\
\text { extensão } \\
(2020)\end{array}$} & Projeto Integrador de Extensão & 50 & - & \multirow{3}{*}{133,3} & \multirow{3}{*}{$69,1 \%$} & \multirow{3}{*}{$30,9 \%$} \\
\hline & Desafio: Edifício Conceitual & 35 & 37 & & & \\
\hline & $\begin{array}{c}\text { Documentação do Projeto } \\
\text { Arquitetônico }\end{array}$ & 7,5 & 3,8 & & & \\
\hline
\end{tabular}

Os conteúdos e atividades $\mathrm{EaD}$ nos componentes curriculares híbridos são selecionados durante o planejamento acadêmico pelos professores que atuam, portanto, como curadores de conteúdo, escolhendo o material sobretudo em uma base de dados adquirida pela IES.

Dentre os diferentes métodos de ensino híbrido, o curso de Arquitetura e Urbanismo adota em especial o modelo de rotação, que alterna entre atividades presenciais e online, complementares entre si. Como um subtipo deste método, é adotado o método da sala de aula invertida, em que conteúdos e exercícios introdutórios são desenvolvidos online, como forma de preparar os estudantes para as atividades desenvolvidas na sala de aula, eminentemente práticas notadamente o projeto de arquitetura. $\mathrm{O}$ modelo de sala de aula invertida é correlato à $\mathrm{ABP}$ (Horn \& Staker, 2015).

A seguir, serão descritos os dois projetos desenvolvidos em anos consecutivos, com objetivos similares e diferentes níveis de presencialidade, observando seus métodos e resultados.

\subsection{Projeto "Meu Lugar"}

A programação do projeto "Meu Lugar", desenvolvido pela turma do segundo período no turno da noite em 2019/2, foi estruturada da seguinte maneira:

- Lançamento da proposta: desenvolver o projeto denominado "Meu Lugar", no qual o aluno escolhe um tema de seu interesse ou algum hobby e projeta esse espaço a partir de suas características e desejos pessoais.

- A escolha do local de implantação é feita pelo aluno e é um projeto individual.

- Esse uso deve ser proposto para se encaixar em um cubo de $6,00 \mathrm{~m}$ x 6,00m x 6,00m.

- Estabelecimento da metodologia de projeto a ser desenvolvida para a realização o projeto estudo dos métodos existentes e sua aplicabilidade.

- Desenvolvimento do estudo preliminar e croquis iniciais (protótipo inicial).

- Avaliação do estudo preliminar.

- Apresentação (seminário) do produto final: anteprojeto arquitetônico com layout na escala 1/50 (integrado com a disciplina Desenho Arquitetônico).

Durante o processo, o aluno aprende e aplica metodologia de projeto - definição do programa de necessidades, elaboração de memorial de intenções, matriz de critérios, diagrama de bolhas 
Citação (APA): Sayd, J. L. C., Canal, P., Filho, \& Costalonga, J. O., Neto. (2021). Aprendizagem baseada em projetos como estratégia de ensino híbrido no curso de arquitetura e urbanismo. Brazilian Journal of Production Engineering, 7(4), Edição Especial: "Educação 5.0: Inovação e metodologias ativas para o ensino superior" 46-64.

- fluxograma e funcionograma, pré-dimensionamento e propriedades e aplicações de materiais construtivos. No caso desse projeto, o principal conteúdo trabalhado foi metodologia de projeto arquitetônico.

Quanto aos resultados, estes foram bastante interessantes, tanto do ponto de vista do resultado formal, quanto do conhecimento das técnicas de desenho e visualização 3D a partir da maquete (Figuras 1 e 2).

Figura 1. Vista isométrica e maquete do projeto "Meu Lugar".

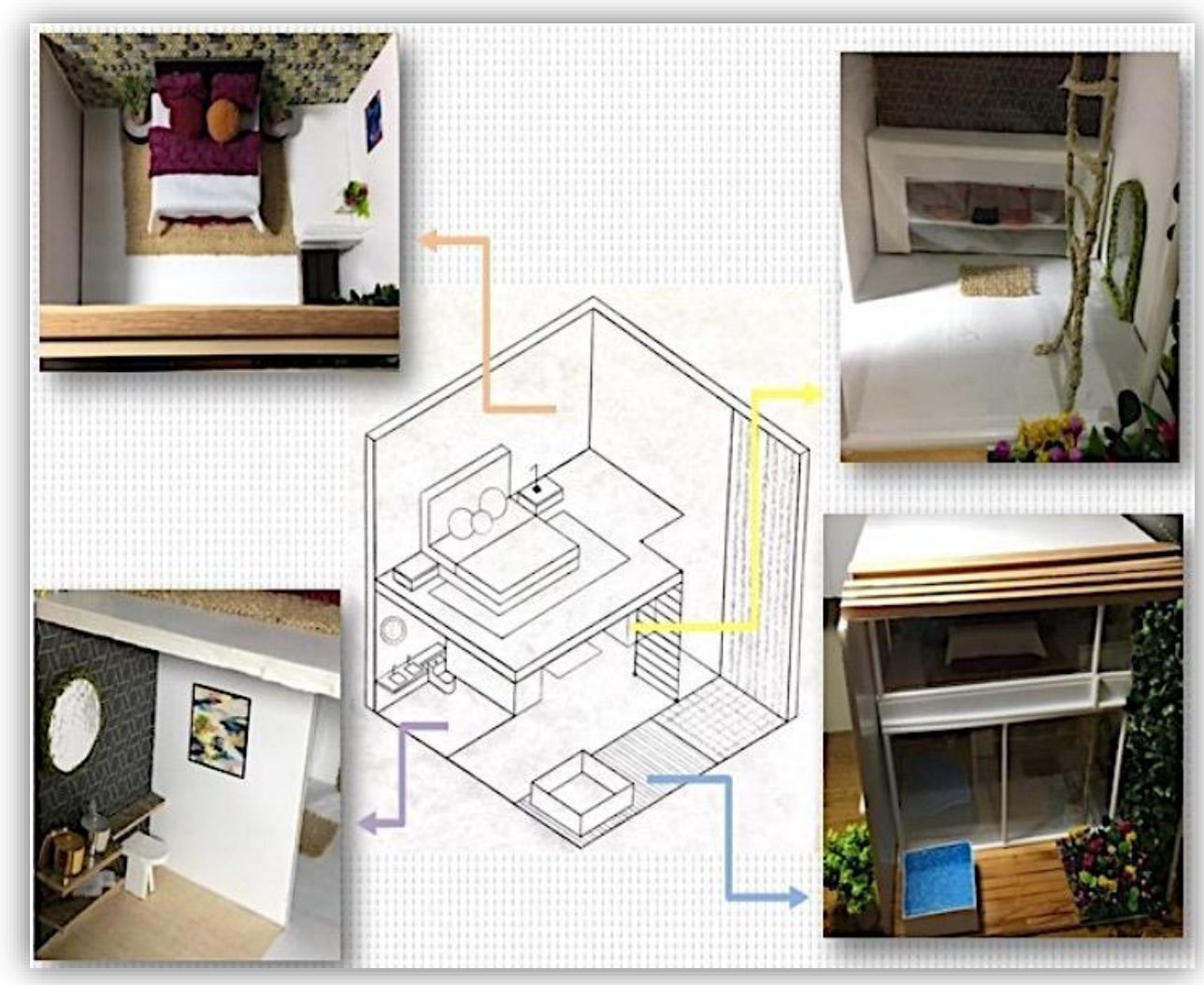

Fonte: Simone Sarah Garcia (2019)

Figura 2. Vista isométrica e maquete do projeto "Meu Lugar".

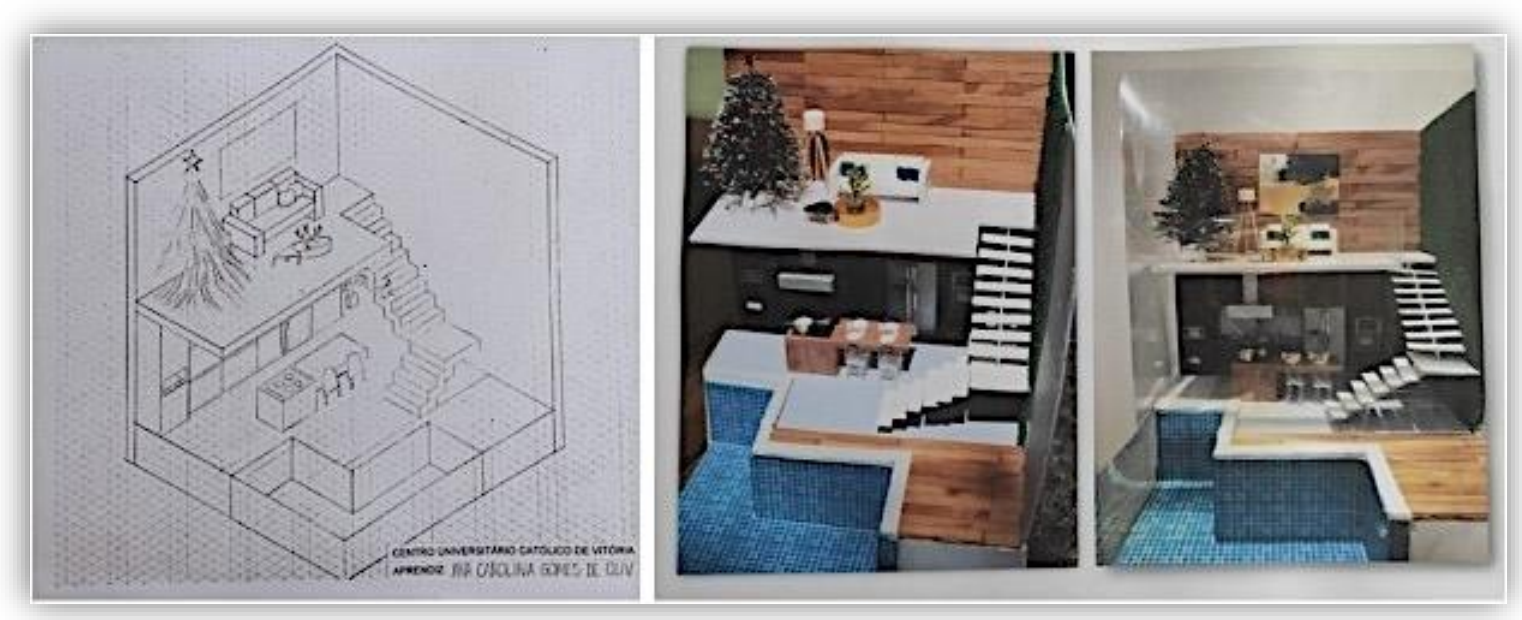

Fonte: Ana Carolina Gomes de Oliveira (2019)

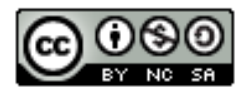


Os estudantes demonstraram sempre muito interesse e dedicação, tendo facilidade de explicar o projeto, uma vez que o mesmo se baseava, obrigatoriamente, em seus gostos e preferências pessoais. Nesse sentido, já foram projetados espaços como salão de beleza, cafeteria, salão de jogos, estúdio de gravação, lojas de roupas, ateliê de design, boate vip, sex shop, pet shop, escritório de arquitetura, loft, floricultura e espaço pet. Assim, essa atividade auxiliou também para o autoconhecimento do estudante e possibilitou que ele se colocasse no lugar de um cliente (ele próprio) com o objetivo de satisfazer seus desejos e intenções num projeto arquitetônico.

A avaliação, de caráter individual, aconteceu em três vertentes - a do professor, que acompanhou todo o processo, com peso de $60 \%$; auto avaliação (20\%) e dos pares (20\%). Desse modo, na apresentação final do trabalho e a partir da exposição da maquete física do projeto, foi distribuída uma ficha para todos os alunos, na qual deveriam avaliar cada projeto, apontando dois pontos positivos e dois pontos negativos ou que deveriam ser melhorados, atribuindo-lhes uma nota de 50 a 100 pontos.

Uma questão que chamou a atenção neste caso foi que os alunos que alcançaram melhores resultados foram aqueles que desenvolveram a atividade de maneira mais equilibrada, estiveram sempre presentes às aulas e tiveram um maior acompanhamento por parte do professor/orientador.

\subsection{Projeto Integrador de Extensão}

A segunda atividade ou desafio analisado foi o Projeto Integrador de Extensão 02, aplicado às turmas de segundo período dos turnos matutino e noturno no semestre de 2020/2. O projeto foi uma demanda real de uma comunidade paroquial e está enquadrado na grade curricular proposta pelo novo modelo pedagógico da IES. Trata-se da elaboração de um projeto de reforma/requalificação de uma igreja católica situada em uma parte carente do bairro onde esta situada a instituição de ensino, com os seguintes objetivos:

- Articular etapas da metodologia de projeto com a demanda proposta;

- Aplicar conceitos de sustentabilidade e desenho universal (estudados anteriormente);

- Estabelecer justa relação entre forma x função x ambientação em um edifício religioso e seus efeitos no espaço construído;

- Perceber a importância da participação da comunidade/demandante na definição do programa e no resultado final do projeto;

- Desenvolver um estudo preliminar para um templo católico para uma paróquia vizinha à IES.

- Aprimorar o trabalho em equipe, no sentido da colaboração e interação.

A programação do Projeto de Extensão 02 das turmas de segundo período em 2020/2 ocorreu da seguinte maneira:

- Apresentação do desafio à turma e organização do trabalho/cronograma previsto;

- Conversa/Entrevista com o demandante (padre da paróquia responsável pela igreja);

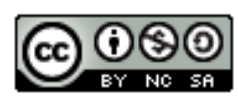


Citação (APA): Sayd, J. L. C., Canal, P., Filho, \& Costalonga, J. O., Neto. (2021). Aprendizagem baseada em projetos como estratégia de ensino híbrido no curso de arquitetura e urbanismo. Brazilian Journal of Production Engineering, 7(4), Edição Especial: "Educação 5.0: Inovação e metodologias ativas para o ensino superior" 46-64.

- Mesa Redonda: Arquitetura Sacra, com mediação do professor/orientador, abordando os seguintes temas: Arquitetura e Simbolismo - a percepção do sagrado (com um arquiteto especialista convidado); e Os espaços religiosos e a liturgia da igreja Católica (com o padre da paróquia);

- Debate com a turma sobre o tema (o que é o espaço religioso e suas principais características e espaços);

- Estudo do local (levantamento do terreno) e análise das condições topográficas e orientação solar e dos ventos predominantes;

- Aplicação de métodos de elaboração de projeto arquitetônico (montagem do programa de necessidades; memorial de intenção; matriz de critérios, diagrama de bolhas - funcionograma e fluxograma, pré-dimensionamento);

- Entrega e discussão do memorial de intenções e dos croquis inicias;

- Orientações na elaboração do projeto - foco em desenho universal e sustentabilidade. Aspectos morfológicos, tipológicos e topológicos/semânticos;

- Entrega final - projeto arquitetônico em nível de estudo preliminar;

- Produção e apresentação de um vídeo de 3 a 5 minutos a ser apresentado em seminário virtual aberto ao público.

Nesta atividade, os problemas e limitações da igreja existente, apresentados pelo pároco no seminário de abertura, foram a âncora da atividade. A necessidade de elaborar um novo projeto para o templo, atendendo aos condicionantes identificados a partir da conversa com o padre e das boas práticas de arquitetura, foi a questão motriz, conforme conceituado por Bender (2014).

Durante o processo, o aluno aprende e aplica metodologia de projeto - definição do programa de necessidades, elaboração de memorial de intenções, matriz de critérios, diagrama de bolhas - fluxograma e funcionograma e pré-dimensionamento. No caso desse projeto, o principal conteúdo trabalhado foi metodologia de projeto arquitetônico aplicada à demanda real da comunidade do Forte São João.

Embora a carga horária presencial tenha diminuído no conjunto do semestre em relação ao semestre da atividade anterior, neste o projeto foi desenvolvido ao longo de todo o período. Esta quantidade de tempo muito maior dedicada ao Projeto Integrador de Extensão 2, em relação ao projeto do "Meu Lugar", se deveu à estratégia de aprofundar a integração entre os componentes curriculares no modelo híbrido, como forma de otimizar o tempo em sala de aula, centralizando o desenvolvimento de competências em torno de uma atividade mais complexa e significativa do ponto de vista técnico e social.

As atividades virtuais do desafio Edifício Conceitual trataram dos métodos de projeto de arquitetura, como a elaboração e o dimensionamento do programa de necessidades e o diagrama de bolhas, fluxograma e funcionograma, além de noções de conforto ambiental, ergonomia e acessibilidade. As atividades $\mathrm{EaD}$ de desenho técnico foram relativas a normas técnicas, em especial anotações e simbologia.

Este projeto teve a particularidade de ser desenvolvido durante o período de distanciamento social decorrente da pandemia de COVID-19. Assim, os dois meses iniciais - agosto e setembro 
Citação (APA): Sayd, J. L. C., Canal, P., Filho, \& Costalonga, J. O., Neto. (2021). Aprendizagem baseada em projetos como estratégia de ensino híbrido no curso de arquitetura e urbanismo. Brazilian Journal of Production Engineering, 7(4), Edição Especial: "Educação 5.0: Inovação e metodologias ativas para o ensino superior" 46-64.

de 2020 - foram realizados através do ensino remoto, por meio de aulas em formato de videoconferência. A partir de meados de setembro de 2020 as aulas passaram a conciliar uma parcela dos alunos em sala de aula, enquanto uma pequena parcela permaneceu acompanhando de maneira remota. Destaca-se que o planejamento acadêmico não contemplou o ensino de ferramentas digitais de projeto representação gráfica. Porém, os estudantes optaram por aprender estas ferramentas de maneira autônoma, e utilizá-las no desenvolvimento do projeto de extensão, não obstante as aulas presenciais tenham sido utilizadas no desenvolvimento de desenhos e maquetes físicas.

Quanto aos resultados, apresentados em um Seminário virtual aberto ao público, por meio de um vídeo elaborado pelos grupos, estes foram bastante interessantes, tanto do ponto de vista do resultado formal, quanto do conhecimento das técnicas de desenho (Figuras 3 e 4).

Figura 3. Plantas baixas e perspectiva digital da igreja católica.

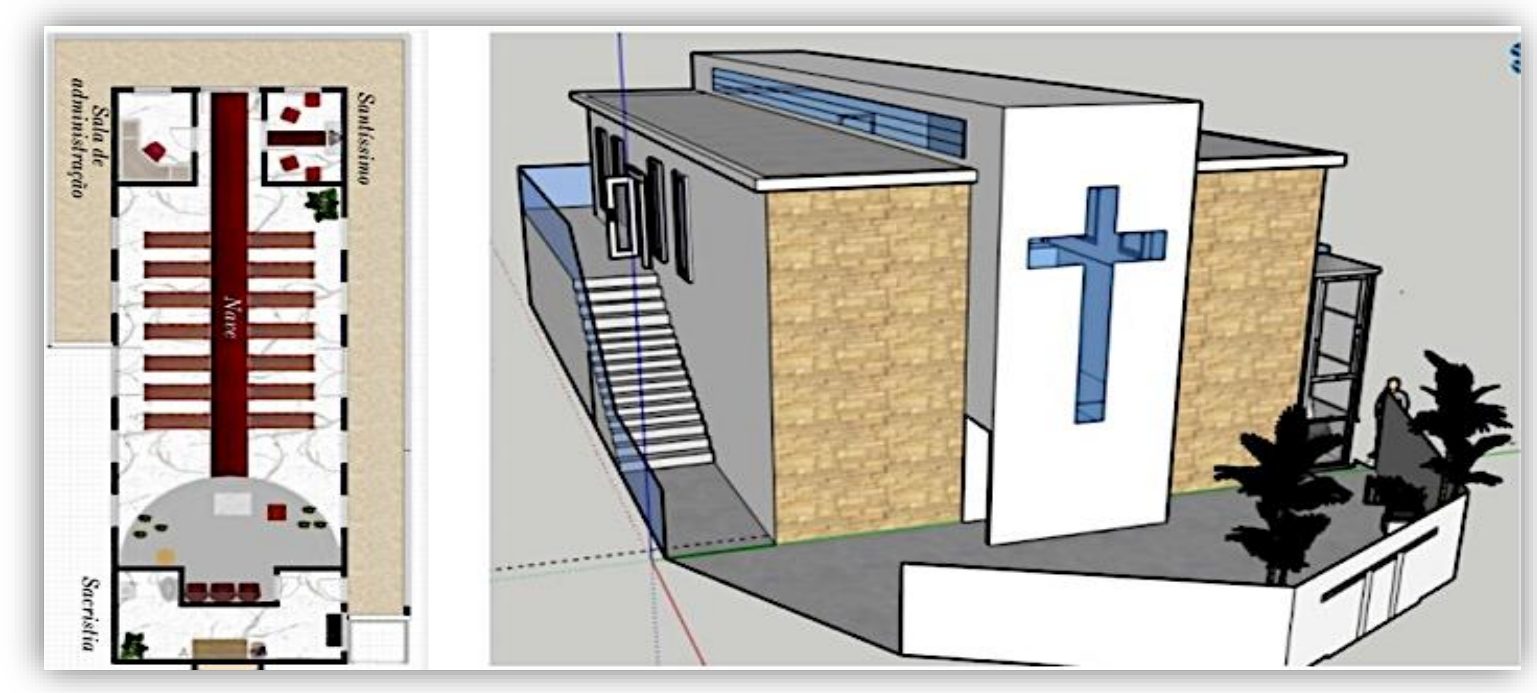

Fonte: Maria Eduarda Loss Cometti, Isabella Serrano Antunes, Thays Ferreira de Oliveira e Yasmin Moreira Borges (2020).

Figura 4. Plantas baixas e perspectiva digital da igreja católica.

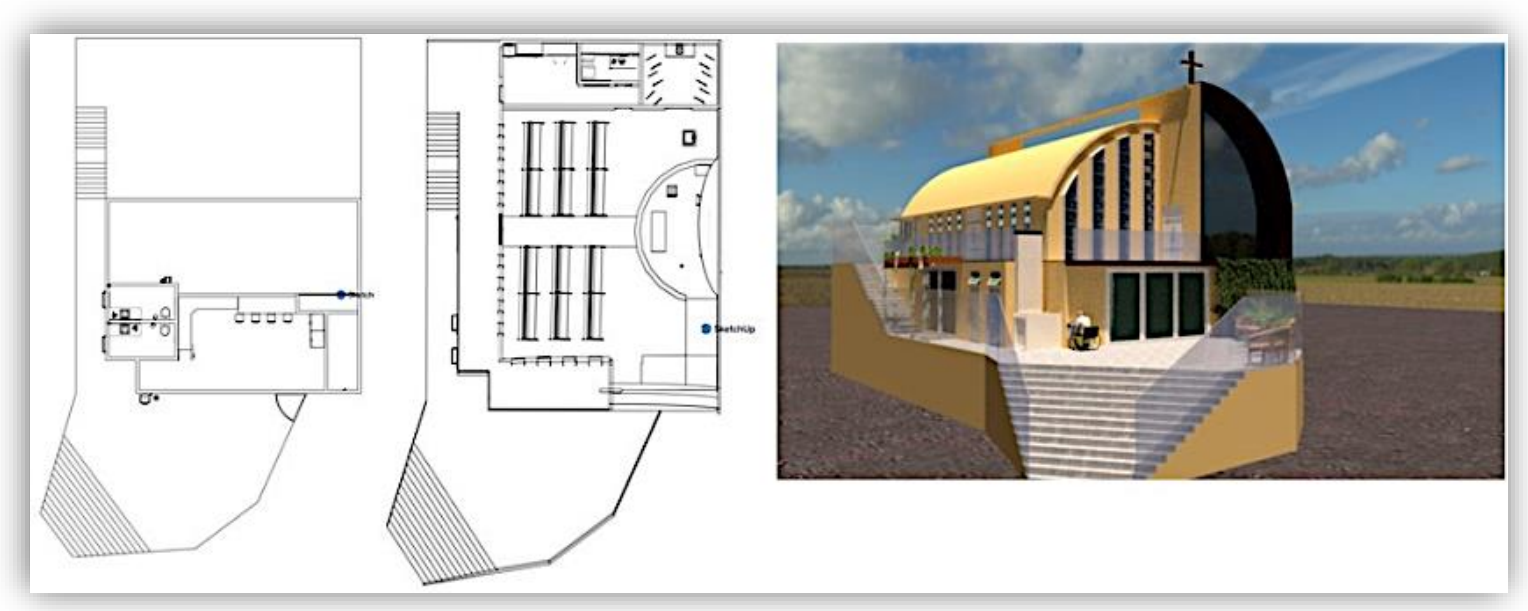

Fonte: Adryelle Compart Januário Pinto, Arthur Vicente Veltem,

Gabrielli Barros Rangel e Gabrielle Rosa Ribeiro (2020).

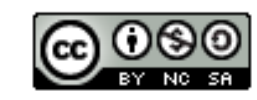


A avaliação, de caráter grupal, aconteceu em três vertentes - a do professor, que acompanhou todo o processo, com peso de $70 \%$; autoavaliação (10\%) e dos pares (20\%).

Uma questão que chamou a atenção neste caso foi a ausência de envolvimento aprofundado do pároco demandante, que só participou de uma reunião inicial, mas não compareceu às reuniões posteriores com as equipes. Para evitar a repetição de situações como esta, os futuros projetos de extensão passaram a contemplar a assinatura de um termo de compromisso entre as partes. Destaca-se que embora o demandante não tenha participado ativamente do processo, persistiram as figuras de outros destinatários, como usuários da igreja projetada, que integram também a comunidade acadêmica, e o público mais amplo, uma vez que os projetos finalizados seriam apresentados em uma mostra de extensão aberta à sociedade civil. Ainda assim, ao contrário do inicialmente planejado, o professor orientador definiu muitas das principais questões que surgiram ao longo do processo. Outra questão que prejudicou o contato dos alunos com a comunidade foi a pandemia de Covid-19, que impediu que fossem realizadas reuniões com o conselho pastoral.

Assim, as demandas foram filtradas e estabelecidas sobretudo a partir dessa conversa inicial com o pároco e do material levantado pelo Núcleo de Projetos da IES, que havia elaborado um levantamento preliminar da área no semestre anterior.

À parte esses contratempos, os projetos obtiveram bons resultados e na avaliação dos próprios estudantes houve crescimento pessoal e aprimoramento técnico, além da gestão do tempo e da organização do trabalho em grupo.

Ao compararmos essas duas atividades, percebemos o quanto elas são complementares, pois é possível avaliar o aluno individualmente ("Meu Lugar") e em grupo (Projeto Integrador de Extensão); há a proposição de projetos reais (Projeto Integrador de Extensão) e fictícios ("Meu Lugar"); mais próximos à realidade (Projeto Integrador de Extensão) e mais abertos aos desejos dos alunos (“Meu Lugar”); demandados pela comunidade (Projeto Integrador de Extensão) ou apenas de interesse particular ("Meu Lugar").

\section{Considerações Finais}

Os cursos de Arquitetura e Urbanismo tradicionalmente desenvolvem projetos que simulam a prática profissional. Projetos de arquitetura, urbanismo, interiores e paisagismo são realizados em terrenos reais, com usos pré-determinados, observando leis e normas, bem como as características da paisagem, infraestrutura, e outros delimitadores do processo construtivo. Porém falta, quase sempre, um ingrediente fundamental da Metodologia Baseada em Projetos: a demanda real.

A falta de destinatários reais para os projetos desenvolvidos ao longo do curso se justifica pela prematuridade dos aprendizes aliada à necessidade de atender aos cronogramas e matrizes curriculares. Estes aspectos dificultam a flexibilização do plano de ensino para o atendimento de demandas reais.

Assim, os professores assumem o papel de construir desafios fictícios, que sejam capazes de proporcionar a aprendizagem pretendida. Torna-se o professor, afinal, o destinatário dos 
projetos desenvolvidos. Apesar das nobres intenções, esta simplificação da realidade limita o desenvolvimento de algumas competências necessárias à formação dos arquitetos e urbanistas - notadamente aquelas relativas ao relacionamento com o usuário, cliente ou público das obras arquitetônicas.

Esta lacuna na formação pode ser preenchida pelos projetos de extensão, que se tornam imperativos para uma formação completa do profissional arquiteto e urbanista. Assim, desde os primeiros anos de formação os aprendizes podem conhecer, dialogar com e compreender os destinatários dos seus projetos, sendo esta aproximação o único modo possível de desenvolver determinadas competências socioemocionais.

Porém, a implementação de projetos de extensão no campo da Arquitetura e Urbanismo envolve grandes desafios, como a dificuldade de encontrar destinatários para projetos que contemplem todas as competências desenvolvidas ao longo do curso, em um fluxo contínuo e adequado aos prazos do calendário acadêmico.

Esses novos projetos exigem também uma mudança no papel do professor, que deixa de ser o destinatário da obra arquitetônica e, portanto, detentor do processo de ensino e avaliação, para tornar-se um mediador, ou facilitador das relações entre os aprendizes e os destinatários do projeto desenvolvido.

Os eventuais conflitos entre arquitetos e destinatários de suas obras, que ocorrem na prática profissional, podem também surgir no âmbito acadêmico, gerando discussões e sentimentos negativos nas pessoas envolvidas. É legítimo e interessante que isso ocorra, pois o objetivo é justamente aproximar os aprendizes da prática profissional e fazer com que lidem da melhor maneira possível com estas situações.

No caso do estudo, um dos maiores desafios para a aplicação integral do método de Aprendizagem Baseada em Projetos (ABP) no primeiro ano do curso de Arquitetura e Urbanismo consiste na resolução de demandas reais ou realistas, pois nesta etapa do curso os aprendizes dedicam-se ao desenvolvimento de projetos mais conceituais, nos quais o foco recai sobre o desenvolvimento da linguagem arquitetônica, da concepção artística e de sua adequada comunicação. Nesta fase inicial do curso, os aprendizes ainda estão desenvolvendo métodos de representação gráfica e projeto arquitetônico. Portanto, o realismo dos projetos nesta fase deve ser ponderado em relação à capacidade dos aprendizes e em especial aos objetivos pedagógicos, que têm na liberdade criativa uma premissa fundamental.

Durante a formação do arquiteto e urbanista é fundamental que haja um momento inicial para maior liberdade criativa, momento este cujas competências essenciais para a futura concepção e elaboração de projetos realistas serão desenvolvidas, dada a circunstância que ao longo do decorrer do curso, e sobretudo da sua carreira profissional, os arquitetos e urbanistas estarão cada vez mais limitados e direcionados pelo cliente, legislação, aspectos construtivos e outros fatores que permeiam a transposição do processo criativo para a materialidade e a realidade que ela reflete.

Deste modo, a aplicação de muitos limitadores, ou balizadores, da criação arquitetônica nesta etapa inicial da formação profissional pode refletir-se em profissionais menos criativos, ou 
incapazes de pensar em soluções espaciais disruptivas, eventualmente capazes de subverter os desejos do cliente, propor alterações na legislação e promover avanços técnicos na construção civil.

Assim, a escolha dos projetos iniciais desenvolvidos no curso de Arquitetura e Urbanismo da IES deve ser acompanhada pelo esclarecimento aos destinatários parceiros quanto à limitação dos estudantes pela falta de experiência e prática projetual, e a provável não aplicação direta dos projetos e desenvolvidos. Além disso, a escolha dos temas deve considerar a possibilidade de desenvolver espaços lúdicos, com apelo mais conceitual, relativo às múltiplas sensações que se pretenda transmitir através do espaço projetado.

Avalia-se que o mais interessante, nessa fase inicial de formação, seja a mescla de atividades e usos de livre escolha do aprendiz (como na proposição do espaço "Meu Lugar") e avaliação individualizada, com atividades voltadas à análise e aplicação prática em situações/problemas existentes - demandados diretamente ou não pela comunidade/agente, desenvolvidas em equipes. Adotando essa prática, a atividade de extensão voltada ao projeto arquitetônico da igreja católica contemplou em uma etapa inicial o desenvolvimento do projeto "Meu Templo Particular", em que os aprendizes desenvolveram projetos similares ao da atividade "Meu Lugar" - individuais e de caráter mais lúdico e livre.

Importa destacar, ainda, que a maior integração entre os componentes curriculares é uma estratégia efetiva na melhoria da formação em Arquitetura e Urbanismo, sobretudo no modelo híbrido. São interessantes a manutenção e o aprofundamento dos projetos de arquitetura e urbanismo como elementos centrais, ou fios condutores, das atividades desenvolvidas ao longo do curso, articulando em torno de si os demais componentes curriculares. Esta abordagem pode simular de forma mais efetiva a prática profissional, produzindo resultados mais consistentes e adequados aos projetos de extensão. Sobretudo, esta integração tem o potencial de otimizar o aproveitamento dos encontros presenciais, que ao relacionar-se de maneira mais efetiva entre si reforçam aprendizagens trabalhadas em diferentes âmbitos, e formam um escopo com maior coesão, identidade e significado para os aprendizes. Estes aspectos contribuem igualmente para um maior engajamento do aprendiz nas atividades desenvolvidas à distância, uma vez que os seus estudos independentes se revestem de maior importância e significado, relativo ao atendimento das demandas reais, bem como à exposição pública do trabalho desenvolvido.

\section{Referências Bibliográficas}

Bender, W. N. (2014). Aprendizagem Baseada em Projetos: Educação Diferenciada para o Século XXI. Porto Alegre: Penso.

Benévolo, L. (2015). História da Cidade (3a ed.). São Paulo: Perspectiva.

Benévolo, L. (1998). História da Arquitetura Moderna. São Paulo: Perspectiva.

Christensen, C. M., Horn, M. B., \& Staker, H. (2013). Ensino Híbrido: uma Inovação Disruptiva? Uma introdução à teoria dos híbridos. San Francisco: Christensen Institute.

Conselho de Arquitetura e Urbanismo do Brasil (CAU/BR). (2019a). Esclarecimento de dúvidas quanto a "cursos semipresenciais". Recuperado de https://www.caubr.gov.br/comissao-de-ensino-e-formacao-esclarece-duvidas-quanto-acursos-semipresenciais 
Citação (APA): Sayd, J. L. C., Canal, P., Filho, \& Costalonga, J. O., Neto. (2021). Aprendizagem baseada em projetos como estratégia de ensino híbrido no curso de arquitetura e urbanismo. Brazilian Journal of Production Engineering, 7(4), Edição Especial: "Educação 5.0: Inovação e metodologias ativas para o ensino superior" 46-64.

Conselho de Arquitetura e Urbanismo do Brasil (CAU/BR). (2019b). Deliberação $n^{\circ}$ 031/2019. Aprova Orientações sobre atividades de Extensão Universitária em cursos de Arquitetura e Urbanismo. Recuperado de https://transparencia.caubr.gov.br/arquivos/deliberacaocep0312019.odt

Costa, T. A. (2004). A noção de competência enquanto princípio de organização curricular. Anais da Reunião Anual da Associação Nacional de Pós-graduação e Pesquisa em Educação, Caxambu, MG, 27.

Hall, P. (2001). Cidades do amanhã: uma história intelectual do planejamento e do projeto urbano no século XX (2. ed.). São Paulo: Perspectiva.

Horn, M. B.; Staker, H. (2015). Blended: Usando a inovação disruptiva para aprimorar a educação. Porto Alegre: Penso.

Leandro, S. M., Corrêa, \& Elisete, M. (2018). Ensino híbrido (blended learning) potencial e desafios no ensino superior. Anais do Congresso Internacional de Educação e Tecnologias, Encontro de Pesquisadores em Educação à Distância, São Carlos, SP, 24.

Masson, T. J.; Miranda, L. F., Munhoz, A. H., Jr., \& Castanheira, A. M. P. (2012). Metodologia de Ensino: Aprendizagem Baseada em Projetos (PBL). Anais do Congresso Brasileiro de Educação em Engenharia, Belém, PA, Brasil, 45.

Ministério da Educação (MEC). (2019). Portaria no 2.117, de 6 de dezembro de 2019. Dispõe sobre a oferta de carga horária na modalidade de Ensino a Distância - EaD em cursos de graduação presenciais ofertados por Instituições de Educação Superior - IES pertencentes ao Sistema Federal de Ensino. Recuperado de http://www.in.gov.br/en/web/dou/-/portaria-n2.117-de-6-de-dezembro-de-2019-232670913

Ministério da Educação (MEC). (2010). Resolução $N^{o}$ 2, de 17 de Junho de 2010. Institui as Diretrizes Curriculares Nacionais do curso de Graduação em Arquitetura e Urbanismo...

Recuperado de http://portal.mec.gov.br/index.php?option=com_docman\&view=download\&alias=5651rces002-10\&Itemid $=30192$

Mumford, L. (2008). A cidade na história: Suas origens, transformações e perspectivas (5 ed.). São Paulo: Martins Fontes.

Presidência da República (2014). Lei $n^{o}$ 13.005, de 25 de junho de 2014. Aprova o Plano Nacional de Educação - PNE e dá outras providências. Recuperado de http://www.planalto.gov.br/ccivil 03/ ato2011-2014/2014/lei/113005.htm

Reese, H. W. (2011). The Learning-by-Doing Principle. Behavioral Development Bulletin, v. 11, 2011. 1-19. https://doi.org/10.1037/h0100597

Reis, F. (Org.). (2017). Destruição Criativa na Educação Superior. Construindo Modelos Inovadores e Sustentáveis Para Além da Crise Econômica. São Paulo: De Cultura.

Ribeiro, L. R. C. (2005). A aprendizagem baseada em problemas (PBL): uma implementação na educação em engenharia na voz dos atores (Tese de Doutorado em Educação). Universidade Federal de São Carlos, São Carlos, SP, Brasil.

Soares, S. G. (2001). Arquitetura da identidade: sobre educação, ensino e aprendizado (2a ed.). São Paulo: Cortez.

Souza, Z. R., \& Biella, J. (2010). Currículo Baseado em Competências. Curso Currículo Contextualizado. Recuperado de https://lagarto.ufs.br/uploads/content attach/path/11338/curriculo baseado em competencias $\underline{\underline{0 . p d f}}$

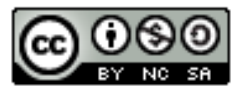

